This is the peer reviewed version of the following article: "Microstructural PALS study of regulated dimethacrylates: Thiol- versus $\beta$-allyl sulfone-based networks", which has been published in final form at https://doi.org/10.1002/polb.24240. This article may be used for noncommercial purposes in accordance with Wiley Terms and Conditions for Use of Self-Archived Versions. 


\title{
Microstructural PALS study of regulated dimethacrylates: Thiol- versus $\beta$-allyl sulfone-based networks
}

\author{
Helena Švajdlenková, ${ }^{* 1}$ Ondrej Šauša, ${ }^{2}$ Johannes Steindl, ${ }^{3}$ Thomas Koch, ${ }^{4}$ Christian Gorsche ${ }^{*, 3,5}$ \\ ${ }^{1}$ Polymer Institute of SAS, Dúbravská cesta 9, 84541 Bratislava, Slovakia \\ ${ }^{2}$ Institute of Physics of SAS, Dúbravská cesta 9, 84511 Bratislava, Slovakia \\ ${ }^{3}$ Institute of Applied Synthetic Chemistry, TU Wien, Getreidemarkt 9/163 MC, 1060 Vienna, Austria \\ ${ }^{4}$ Institute of Materials Science and Technology, TU Wien, Getreidemarkt 9/308, 1060 Vienna, Austria \\ ${ }^{5}$ Christian-Doppler-Laboratory for Photopolymers in Digital and Restorative Dentistry, Getreidemarkt 9, \\ 1060 Vienna, Austria \\ *Correspondence to: H. Švajdlenková (helena.svajdlenkova@savba.sk) or C. Gorsche \\ (christian.gorsche@tuwien.ac.at)
}

((Additional Supporting Information may be found in the online version of this article.))

\begin{abstract}
Radical photocuring of multifunctional (meth)acrylates is lacking control over the irregular chain growth process yielding highly crosslinked, inhomogeneous networks. Chain transfer agents (CTAs, e.g. thiols or $\beta$-allyl sulfones) have been widely used to modify this curing process, thus reducing shrinkage stress and increasing the toughness of the formed photopolymers. Resulting photopolymer networks exhibit higher bulk density, lower crosslinking density and narrow glass transitions. Consequently, a more homogeneous network structure was postulated for those networks. Whereas macroscopic properties of the modified final materials have already been studied, herein the microstructural arrangement of such modified networks has also been evaluated with the help of positron annihilation lifetime spectroscopy (PALS). A more homogenous network structure with a decreased free-volume void size was confirmed for CTA-based dimethacrylate networks. A sharper distribution of the orthopositronium (o-Ps) lifetime, mainly for the $\beta$-allyl sulfone-based photopolymers, hints towards a more regulated network structure. Moreover, the combination of PALS, DMTA, density and swelling experiments elucidates relations between void formation, crosslinking density and macroscopic characteristics such as shrinkage stress and mechanical properties.
\end{abstract}

KEYWORDS: photopolymerization; structure-property relations; addition fragmentation chain transfer; Mc value; positron annihilation

\section{INTRODUCTION}

Photopolymerization is an excellent technique for the rapid formation ( $<5$ s) of highly crosslinked networks, which have found use in a wide variety of applications such as protective and decorative coatings ${ }^{1}$, in the biomedical field ${ }^{2}$ or 3D printing. ${ }^{3}$ Due to their low toxicity and high heat deflection temperature methacrylates are often preferred over acrylates when working towards sensitive applications. The photopolymerization of dimethacrylates usually creates inhomogeneous and rather brittle polymer networks via its radical chain growth mechanism. ${ }^{4}$ The characteristic for commonly used photopolymers is that the gelation occurs at low conversion ( $<20 \%$ ), which is accompanied by subsequent shrinkage causing stress in the cured network. The resulting materials exhibit 
broad thermal phase transitions and low impact resistance.

Regulating the photopolymerization of dimethacrylates with chain transfer agents (CTAs) yields modified network structures via the introduction of a mixed radical chain growth / step growth-like mechanism also leading to increased double bond conversion. There are two major classes of CTAs for methacrylatebased network regulation stated in literature, thiols $^{5}$ and addition fragmentation chain transfer (AFCT) reagents. ${ }^{6}$ The CTA terminates a growing polymer chain and forms a new reactive radical that can start a new chain, thus generating shorter polymer backbones. Recently, aside from the widely known thiolene approach, $\beta$-allyl sulfones have been described as a very potent type of CTA for the regulation of methacrylate-based photopolymer networks. ${ }^{7}$ Additionally to their obvious benefits such as neutral odor and good storage stability, $\beta$-allyl sulfones yield regulated methacrylate networks which exhibit sharper thermal glass transitions, reduced shrinkage stress as well as higher impact resistance compared to corresponding thiol-ene networks. $^{8}$

The view into the molecular structure of such networks is not common but to look more deeply into the microstructure of such regulated photopolymer networks can significantly contribute to the understanding of the obtained physical and mechanical properties. Positron annihilation lifetime spectroscopy (PALS) serves as a valuable tool for the investigation of said microstructure. ${ }^{9,10}$ Previous PALS studies on thermosetting materials were mostly focused on cured epoxy networks where crosslinking reduced the size of voids, increased the bulk density and the glass transition temperature $\left(\mathrm{T}_{\mathrm{g}}\right)^{11}$

Limited PALS investigations have been performed on radically cured crosslinked networks which have been formed by polymerization of at least one multifunctional monomer. One of the first PALS studies on such resins was published by Dlubek et al. ${ }^{12}$ where it was found that the free-volume voids in poly(diethylene glycol bis(allyl carbonate)) networks were enlarged by increasing the weight concentration of the monoallyl comonomer. Moreover, the addition of the monofunctional comonomer decreases the $T_{g}$ and increases the specific volume that corresponds with the lowering of the crosslinking density. C. S. Pfeifer et al. ${ }^{13}$ elucidate the crosslinking structure in a series of dimethacrylate polymer networks consisting of two monomers, bisphenol A glycol dimethacrylate (BisGMA) and a varying triethylene glycol dimethacrylate (TEGDMA) content. The increase of the comonomer amount TEGDMA increases free-volume voids due to a higher rotational tendency and also the engagement of cyclization reactions. As a result, samples with a higher TEGDMA amount exhibit a looser network structure with poorer polymer packing ability. On the other hand, BisGMA with the rotationally hindered aromatic rings tends to pack free-volume. This can also be explained by the $\pi-\pi$ stacking interactions between aromatic rings as well as stronger $\mathrm{H}$-bonding interactions for BisGMA-based networks. Thiolene networks have also already been studied with PALS showing similar trends. By using monofunctional monomers with larger alkyl groups, the void volume size is increased. ${ }^{14}$ However, there have not been any studies reported on thiol-ene networks with multifunctional thiols, which yield crosslinked networks with more defined network architectures.

In this work, a comparative study between regulated dimethacrylate networks has been performed, using a dithiol (2,2' (ethylenedioxy)diethanethiol, EDDT) and a difunctional $\beta$-allyl sulfone (DAS) as potent CTAs. A mixture of two commercial dimethacrylates (urethane dimethacrylate, UDMA and 1,10-decanediol dimethacrylate, D3MA) was used as reference formulation. Previously, we investigated the macrostructure of regulated methacrylate-based 
photopolymers with DMTA and swellability tests. ${ }^{7}$ Additionally, mechanical properties such as hardness and impact resistance were tested. ${ }^{8}$ Herein we report a more detailed analysis of the macrostructure by means of bulk density, the swellability of networks and the behavior of glass transition as seen by dynamic mechanical analysis (DMA). In addition, the molecular weight between crosslinks $\left(M_{c}\right)$ was estimated through swelling behaviour as well as the storage elastic modulus in the rubbery region $\left(E_{r}^{\prime}\right)$ from DMA. Finally, the microstructure of the photopolymers was investigated via the free volume void size and their distribution using PALS. The global information about microstructure and macroscopic parameters (e.g. polymerization induced shrinkage stress, mechanical properties) should improve our understanding about the influence of network architecture on the final material properties.

\section{EXPERIMENTAL}

\section{Materials}

The photoinitiator bis(4-methoxybenzoyl)diethylgermanium (Ivocerin), ${ }^{15}$ the acidic monomer (2-((2-(ethoxycarbonyl)allyl)oxy)ethyl)phosphonic acid (MA), and the monomers urethane dimethacrylate (UDMA, isomeric mixture, CAS: 72869-86-4) and 1,10-decanediol dimethacrylate (D3MA) were kindly provided by Ivoclar Vivadent AG. 2,2' (Ethylenedioxy)diethanethiol (EDDT) and pyrogallol (PG) were purchased from Sigma-Aldrich. The difunctional $\beta$-allyl sulfone (DAS) was synthesized according to literature using triethylene glycol dimethacrylate as precursor (see $\mathrm{SI}){ }^{7}$

\section{Preparation of cured samples for DMA and PALS measurements}

An equimolar mixture of UDMA and D3MA (2M) was prepared. In the case of chain transferbased samples, 25 mol\% of CTA (EDDT or DAS, thiol-based samples were additionally stabilized using $9 \mathrm{mM}$ PG and $90 \mathrm{mM} \mathrm{MA})^{16}$ were also added to the formulation. Then $1 \mathrm{~mol} \%$ Ivocerin was added to each formulation and the three resins were mixed in an ultra-sonic bath for 20 min at room temperature. The average molar mass of the sample mixtures $M_{s}$ (eq 1 ) was calculated from the mole fractions $x_{i}$ of the individual components (eq 2). $M_{s}$ then was applied for the determination of packing density ( $\left.\rho_{\text {packing }}\right)$ (Table 1$)$ and the solubility parameter of the samples $\left(\delta_{p}\right)$ (Table 2$)$. For the calculation of $\rho_{\text {packing }}$ and $\delta_{p}$ see eq S1 and S2 in the supporting information.

$$
\begin{aligned}
& M_{s}=\sum x_{i} M_{i}=x_{A} M_{A}+x_{B} M_{B}+x_{C} M_{C} \\
& x_{A}=\frac{n_{A}}{\sum n_{i}}
\end{aligned}
$$

For DMA, the reference resin $2 \mathrm{M}$ and the two CTA-based formulations, 2M/DAS and $2 \mathrm{M} / \mathrm{EDDT}$, were poured into a rectangularshaped silicone mold $\left(\sim 5 \times 2 \times 40 \mathrm{~mm}^{3}\right)$. For PALS experiments, the resins were placed in a round silicone mold $(\varnothing \sim 15 \mathrm{~mm}$, thickness $3 \mathrm{~mm}$ ). All samples were then cured for $20 \mathrm{~min}$ in a Lumamat 100 light oven (provided by Ivoclar Vivadent AG) with six Osram Dulux L Blue $18 \mathrm{~W}$ lamps. The emitted wavelength spectrum covered the range of $400-560 \mathrm{~nm}$ with a total intensity of $\sim 20 \mathrm{~mW} \mathrm{~cm}^{-2}$, measured by using an Ocean Optics USB 2000+ spectrometer.

\section{Density measurements}

The bulk density of the dimethacrylate networks was determined by gravimetric method (based on the Archimedean principle) where cut samples from the PALS discs were immersed into ethanol. The bulk density of a given sample, $\rho$ is calculated on the basis of eq 3:

$\rho=\rho_{E t O H}\left[\frac{m_{0}}{m_{0}-m_{1}+m_{\text {wire }}}\right]$

where $\rho_{\mathrm{EtOH}}$ is the density of ethanol at ambient temperature, $m_{\text {wire }}$ is the weight of the wire in 
EtOH and the values of $m_{0}$ and $m_{1}$ are the sample weights in air and immersed in ethanol, respectively.

\section{Swelling tests}

For swelling tests, three cured samples (cut from PALS discs, thickness $\sim 3 \mathrm{~mm}$ ) of known weight $\left(\mathrm{m}_{0}\right)$ were immersed in two liquids: anhydrous ethanol (EtOH) and chloroform $\left(\mathrm{CHCl}_{3}\right)$. Approximately $200 \mathrm{ppm}$ of hydroquinone was added to the swelling liquids to prevent post polymerization of the residual double bonds. The swelling procedures were carried out at ambient temperature for 8 days to attain equilibrium. Then the samples were weighed ( $\left.\mathrm{m}_{\text {swollen }}\right)$ and dried at $60{ }^{\circ} \mathrm{C}$ in a vacuum oven until constant weight was reached $\left(m_{\text {dry }}\right)$. The percent equilibrium mass swelling $(S)$ follows the eq 4 :

$$
S=\left[\frac{m_{\text {swollen }}-m_{\text {dry }}}{m_{d r y}}\right] \times 100
$$

The molecular weight between two crosslinks $M_{c}$ was calculated from Flory-Rehner equation (eq 5): ${ }^{17}$

$$
v=\frac{1}{M_{c}}=-\left[\frac{\left(V_{r}+\chi V_{r}^{2}+\ln \left(1-V_{r}\right)\right)}{\rho_{p} V_{0}\left(V_{r}^{1 / 3}-\frac{V_{r}}{2}\right)}\right]
$$

where $u$ is the crosslinking density, $\rho_{p}$ is the bulk density of the polymeric sample and $V_{r}$ is the volume fraction of the polymer in the swollen state, that is given by eq 6 and 7 .

$$
\begin{aligned}
& V_{r}=\frac{1}{(1+Q)} \\
& Q=\left[\frac{\left(m_{\text {swollen }}-m_{0}\right) \rho_{p}}{m_{0} \rho_{\text {liquid }}}\right]
\end{aligned}
$$

where $\rho_{\text {liquid }}$ is the density of the liquid and $V_{0}$ is the molar volume of the liquid. For $\mathrm{EtOH}$ and $\mathrm{CHCl}_{3}, \mathrm{~V}_{0}$ is $57.62 \mathrm{~cm}^{3} \mathrm{~mol}^{-1}$ or $81 \mathrm{~cm}^{3} \mathrm{~mol}^{-1}$, respectively. The parameter $\chi$ is the FloryHuggins interaction parameter between the polymer and the liquid. Its value for polymeric- liquid systems was calculated by using the cohesive energy of partial atomic groups from the monomer. ${ }^{18}$

\section{Dynamic mechanical analysis (DMA)}

The storage modulus and the loss factor for the measured photopolymers were determined using a TA Q800 in tensile mode. Samples were tested with a frequency of $1 \mathrm{~Hz}$ and a dynamic deformation amplitude of $0.05 \%$ (ratio of static to dynamic load $=1.25$ ). The temperature profile started at $150 \mathrm{~K}$ and was increased to $423 \mathrm{~K}(2 \mathrm{M} / \mathrm{DAS}, 2 \mathrm{M} / \mathrm{EDDT})$ or $473 \mathrm{~K}(2 \mathrm{M})$ with a heating rate of $2 \mathrm{~K} \mathrm{~min}^{-1}$.

\section{Positron annihilation lifetime spectroscopy (PALS)}

PALS technique provides information about the free volume microstructure of polymeric materials which is a valuable tool for the development of new and innovative materials. This method is based on the lifetime measurements of a positron or an atomic positronium probe ( $P s$, the bound state of $\mathrm{e}^{+}$ and $\left.\mathrm{e}^{-}\right)$in the investigated material. The typical PALS spectra of polymers usually consist of three lifetime components connected with annihilation of para-positronium ( $p-P s)$, free positronium $\left(\mathrm{e}^{+}\right.$) and ortho-positronium (o-Ps), where o-Ps lifetime, as the longest component, is the main indicator of the local region with low electron density, e.g. voids. Consequently, the measured lifetime enables the estimation of void sizes by suitable models. ${ }^{10}$

The positron annihilation lifetime spectra were obtained by a conventional fast-fast coincidence spectrometer with a time resolution of $320 \mathrm{ps}$ at $\mathrm{w}_{1 / 2 \mathrm{~h}}$ (full width at half height of the resolution curve). A modelindependent instrumental resolution function was obtained from annihilation spectra of an Al defect-free sample with a single lifetime of $166 \mathrm{ps}$. The radioactive positron ${ }^{22} \mathrm{Na}$ source (activity of $0.8 \mathrm{MBq}$ and an active area of $\sim 8 \mathrm{~mm}$ ) is sandwiched between two samples. PALS experiments were carried out in air at 
296 K. Total irradiation dose for each sample was about $21 \mathrm{~Gy}$. Total time of exposition was $24 \mathrm{~h}$. The positron lifetime spectra were analyzed by the MELT ${ }^{19}$ program which assumes<smiles>C=C(C)C(=O)OCCOC(=O)NCCC(C)CC(C)(C)CNC(=O)OCCOC(=O)C(=C)C</smiles><smiles>C=C(C)C(=O)OCCCCCCCCCOC(=O)C(=C)C</smiles>

continuous lifetime distribution, as well as the discrete term-analysis by using the PATFIT- 88 software package. $^{20}$
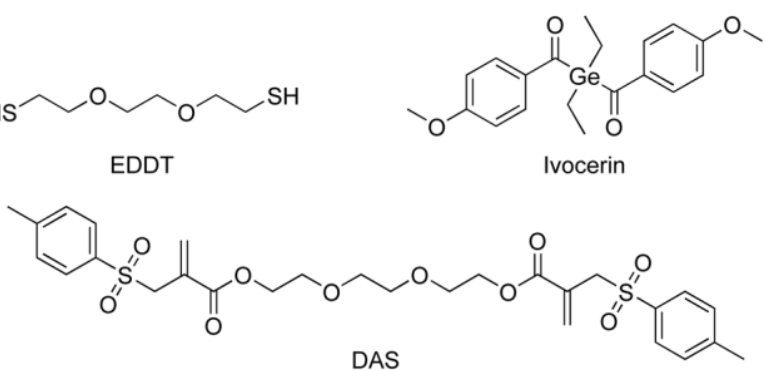

FIGURE 1 Chemical structures of the two dimethacrylates D3MA and UDMA (reference resin, 2M), the dithiol (EDDT), the difunctional $\beta$-allyl sulfone (DAS) and the used photoinitiator Ivocerin.

In the framework of free-volume interpretation of ortho-positronium (o-Ps) annihilation in matter and the standard quantum-mechanical model of o-Ps annihilation in spherical freevolume hole, the o-Ps lifetime $\tau_{o-P s}$ is related to the free-volume void size $r_{h}$ as follows (eq 8):21,22

$\tau_{o-P S}=0.5\left\{1-\frac{r_{h}}{\left(r_{h}+\Delta R\right)}+\left(\frac{1}{(2 \pi)}\right) \sin \left[\frac{2 \pi r_{h}}{\left(r_{h}+\Delta R\right)}\right]\right\}^{-1}$

where $\Delta R$ with $1.66 \AA$ is the thickness of the electron layer on the surface of a free-volume hole which was determined from calibration of known free-volume vacancies in molecular crystals and zeolites. In reality, the shape of free-volume holes is not spherical, so eq 8 is applied in the sense of the mean o-Ps lifetime that is used to estimate the equivalent mean void radius. The corresponding mean hole volume is given by eq 9 :

$V_{h}=\frac{4}{3} \pi r_{h}^{3}$

Thus, the PALS technique allows the extraction of the free-volume characteristics such as the mean free-volume void sizes $r_{h}$ from the o-Ps lifetime. $^{21-23}$

\section{RESULTS \& DISCUSSION}

Crosslinked methacrylate-based photopolymers suffer from high shrinkage stress and low toughness originating from their fast gelation already at conversions $<20 \%$, leading to inhomogeneous network architectures. The implementation of CTAs gives access to materials with modified network structures and tunable mechanical properties. $\beta$-Allyl sulfones have been recently introduced as potent CTAs for the regulation of highly crosslinked dimethacrylate networks. ${ }^{7,8}$ Following up these studies, the microstructure of such regulated dimethacrylate networks will herein be evaluated using PALS. The photopolymer network of UDMA and D3MA (i.e. equimolar reference formulation $2 \mathrm{M}$ ) and photopolymers with additional CTA, $\beta$-allyl sulfone (2M/DAS) or dithiol (2M/EDDT), in the molar content of $25 \%$ were analyzed (Figure 1). Results for the networks were put in comparison towards each other. For the photopolymerization of the three resins, the visible light initiator Ivocerin was used (1 mol\%).

A schematic draft of the changed network architecture resulting from a mixed radical chain growth / step growth-like photopolymerization process using CTAs is outlined (Figure 2 right) in correlation to an inhomogeneous dimethacrylate network 
structure formed by irregular radical chain growth photopolymerization (Figure 2 left). A detailed description on the radical mechanisms involved during the photopolymerization reactions using difunctional $\beta$-allyl sulfones or dithiols can be seen in recent literature. ${ }^{7,8}$
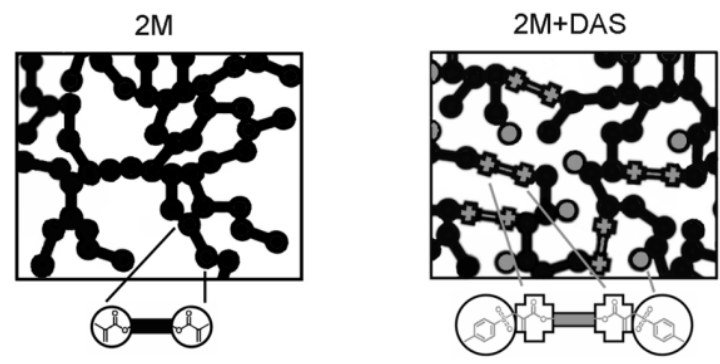

FIGURE 2 Schematic picture of a dimethacrylate network (left) and a regulated network using the difunctional $\beta$-allyl sulfone DAS (right).

\section{Density characterization}

\section{Packing density of samples at room temperature}

It is expected that void size could be influenced by the packing ability (i.e. packing density of the molecular segments). The values of $\rho_{\text {packing }}$ for all three tested systems are comparable and in the range of $0.71-0.73$ (Table 1 , see $\mathrm{SI}$ ). Those values, which are not far from the average value 0.68 for amorphous polymers ${ }^{24}$ indicate a similar packing efficiency for the samples. It is know that the packing density in resins is strongly dependent on the composition of aliphatic chains with more or less cohesive groups such as hydroxyl- $(\mathrm{OH})$, amino-groups (NH) and aromatic rings. ${ }^{25}$ In the case of the CTA-modified networks, the thiol bridges in the 2M/EDDT sample exhibit a lower cohesive energy (1658 $\mathrm{cal}^{1 / 2} \mathrm{~cm}^{-2 / 3} \mathrm{~mol}^{-1}$ ) compared to the network 2M/DAS $\left(5327 \mathrm{cal}^{1 / 2} \mathrm{~cm}^{-2 / 3} \mathrm{~mol}^{-1}\right)$. This might explain the slight decrease of the packing efficiency $\rho_{\text {packing }}$ for $2 \mathrm{M} / \mathrm{EDDT}$.

\section{Bulk density}

The bulk density $\rho_{p}$ of the three photocured samples shows that the DAS-based polymer has a higher $\rho_{p}$ value (Table 1 ). The values for $2 \mathrm{M}$ and 2M/EDDT are similar and the evident higher $\rho_{p}$ of $2 \mathrm{M} / \mathrm{DAS}$ implies a more densely packed network structure. Hence, the macroscopic specific volume $\left(V_{s p}=1 / \rho_{p}\right)$ from density measurements shows a decreasing trend with the presence of CTAs. Moreover, the different curing mechanisms of photopolymerizations with the two CTA-based resins $^{8}$ lead to a reduction in shrinkage stress thus contributing to a denser network architecture by shifting the gelation to higher conversion. It is also important to mention that the $\beta$-allyl sulfone DAS with its aromatic $\mathrm{SO}_{2}$ groups could yield chains which are more ordered and stacked (lowering of inter-chain space).

TABLE 1 Packing density $\rho_{\text {packing, }}$ bulk density $\rho_{\mathrm{p}}$, and average molar mass of the resins $M_{s}$ for all three networks tested.

\begin{tabular}{cccc}
\hline sample & $\begin{array}{c}\mathrm{M}_{\mathbf{s}} \\
/ \mathrm{g} \mathrm{mol}^{-1}\end{array}$ & $\rho_{\text {packing }}$ & $\begin{array}{c}\rho_{\mathrm{p}} \\
/ \mathrm{g} \mathrm{cm}^{-3}\end{array}$ \\
\hline 2M & 390.51 & 0.725 & $1.145 \pm 0.003$ \\
\hline 2M/EDDT & 338.45 & 0.713 & $1.154 \pm 0.005$ \\
\hline 2M/DAS & 441.55 & 0.723 & $1.196 \pm 0.009$ \\
\hline
\end{tabular}

\section{Swelling experiments}

The crosslinking density of the tested polymer specimens was estimated by swelling experiments. Pieces from the measured PALS samples were cut with a thickness of $\sim 3 \mathrm{~mm}$ and dispensed in anhydrous ethanol (EtOH) or chloroform $\left(\mathrm{CHCl}_{3}\right)$ until equilibrium swelling was reached. The swellability $\mathrm{S}$ was calculated for the three photopolymer networks. The solubility parameters $\delta_{p}$ used in predicting the solubility of the three photopolymer networks in a given liquid were estimated by using the cohesive energies for the partial atomic groups of the monomer (eq S2). ${ }^{18}$

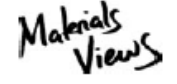

WWW.MATERIALSVIEWS.COM 
TABLE 2 Solubility parameter of the samples $\delta_{p}$, their swellability (S) in $\mathrm{EtOH}$ (anhydrous) and in $\mathrm{CHCl}_{3}$ and resulting $\mathrm{M}_{\mathrm{c}}$ values from $\mathrm{CHCl}_{3}-$ swelling.

\begin{tabular}{|c|c|c|c|c|}
\hline sample & $\begin{array}{c}\delta_{\mathrm{p}} \\
/ \mathrm{cal}^{1 / 2} \mathrm{~cm}^{-3 / 2}\end{array}$ & $\begin{array}{l}S_{\text {EtoH }} \\
/ \%\end{array}$ & $\begin{array}{c}\mathrm{S}_{\mathrm{CHCl} 13} \\
/ \%\end{array}$ & $\begin{array}{l}\mathrm{M}_{\mathrm{c}(\mathrm{CHCl})} \\
/ \mathrm{g} \mathrm{mol}^{-1}\end{array}$ \\
\hline $2 \mathrm{M}$ & 9.90 & $1.9 \pm 0.2$ & $10.8 \pm 0.1$ & 43 \\
\hline 2M/EDDT & 9.97 & $11.0 \pm 0.3$ & $83.4 \pm 0.7$ & 228 \\
\hline $2 \mathrm{M} / \mathrm{DAS}$ & 9.94 & $5.2 \pm 0.3$ & $80.6 \pm 0.4$ & 295 \\
\hline
\end{tabular}

The behaviour of the samples in anhydrous EtOH with a solubility parameter $\delta_{\mathrm{EtOH}}=12.7$ is in relation to previous studies. ${ }^{7}$ On the other hand chloroform with $\delta_{\mathrm{CHCl} 3}=9.3$ manifested a higher interaction for dimethacrylate-based materials. This corroborates the close values of the solubility parameters between all three photopolymer samples and chloroform (Table 2). The CTA/dimethacrylate networks exhibit higher swelling properties than the reference sample $2 \mathrm{M}$ in both abovementioned liquids. The lower swellability $S$ for the reference network $2 \mathrm{M}$ confirms a more densely crosslinked structure compared to more flexible network structures in CTA-based systems, which exhibit much higher S. Moreover, chain entanglements need to be taken into consideration as they contribute considerably to the mechanically effective crosslinks in the polymer networks studied.

A higher swellability for the CTA-based networks can be attributed to the higher mobility of chains and reduced physical entanglements due to the more homogeneous network structure and smaller average kinetic chain length in these systems (Figure 2). The molecular weight between crosslinks $M_{c}$ (determined from swelling experiments in $\mathrm{CHCl}_{3}$ ) reflects all mechanically effective crosslinks including chain entanglements. The reference $2 \mathrm{M}$ which is made up by dimethacrylates exhibits with $43 \mathrm{~g} \mathrm{~mol}^{-1}$ the lowest $M_{c}$ value. Due to the introduced network regulation for the CTA-based photopolymer networks their overall crosslinking density is lower which is further confirmed by increased $M_{c}$ values. The $\beta$-allyl sulfone-based photopolymer 2M/DAS exhibits with an $M_{c}$ value of $295 \mathrm{~g} \mathrm{~mol}^{-1}$ an even lower crosslinking density than the thiol-based network 2M/EDDT. The $M_{c}$ value is dependent on the molecular weight of EDDT and DAS, respectively. The higher molecular weight of DAS could be an explanation for a higher $M_{c}$ value compared to EDDT-based samples. The spacer in between crosslinks for the two CTAs was chosen to be as similar as possible to minimize this effect. Moreover, the possible additional crosslinks due to subsequent reaction of the newly formed double bonds on the DAS spacer is postulated to have a much more significant effect on the $M_{c}$ value than the difference in molecular weights, thus confirming the higher $\mathrm{M}_{\mathrm{c}}$ value for $2 \mathrm{M} / \mathrm{DAS}$.

The density measurements at ambient conditions $\left(T<T_{\mathrm{g}}\right)$ revealed a more dense structure for the 2M/DAS sample than for $2 \mathrm{M} / \mathrm{EDDT}$ or $2 \mathrm{M}$ samples. We can also see the influence of more or less polar groups $\left(\mathrm{SO}_{2}, \mathrm{SH}\right)$ probably similar to the work of Pethrick. ${ }^{9}$ Therefore, at temperatures below $T_{g}$ the $\beta$-allyl sulfone-based sample (2M/DAS) has chains closer together than in the dithiol based sample (2M/EDDT). However, the swelling experiment shows the structure at different conditions. The attractive forces (physical bonds) in the sample are repealed and we can see the so-called unpacked structure. It is given by the cohesive energy of the samples as well as by the interaction parameter between chains and absorbed liquid. Moreover, the uncertainty on the $M_{c}$ values can be attributed to the Flory Huggins interaction $\chi$ parameter used in eq 5 which is highly sensitive to slight changes. Both, the swellability and $M_{c}$ values of CTA-based samples strongly indicate a less crosslinked network in comparison to the cured dimethacrylate sample $2 \mathrm{M}$. 


\section{Dynamic mechanical analysis (DMA)}

The pure dimethacrylate network and the CTAbased photopolymers were characterized towards their thermo-mechanical properties by DMA over a wide temperature range from $173 \mathrm{~K}\left(-100^{\circ} \mathrm{C}\right)$ up to $423 \mathrm{~K}\left(150^{\circ} \mathrm{C}\right)$. The storage modulus $\left(E^{\prime}\right)$ and loss factor $(\tan \delta)$ plots of the CTA containing resins exhibit a more homogeneous network architecture compared to the dimethacrylate reference $2 \mathrm{M}$ (characterized by a narrow $\mathrm{w}_{1 / 2 \mathrm{~h}}$ width of glass transition at half height in the loss factor curve). ${ }^{8}$ The incorporation of CTAs also reduces the glass transition temperature $\left(T_{g}\right)$ and the rubbery modulus $\left(E_{r}^{\prime}\right)$ which are influenced by several factors such as crosslinking density, flexibility of chains, molecular weight, polarity of groups, unreacted double bonds and freevolume (Table 3 and Figure 3).

TABLE 3 Glass transition temperature $\left(T_{g}\right)$, full width at half maximum of the loss factor curve $\left(w_{1 / 2 h}\right)$, storage modulus at $293 \mathrm{~K}\left(E^{\prime}{ }_{293}\right)$ and at the rubbery state $\left(E_{r}{ }_{r}\right)$ and molecular weight between crosslinks $\left(\mathrm{M}_{\mathrm{c}}\right)$.

\begin{tabular}{|c|c|c|c|c|}
\hline sample & $\begin{array}{c}\mathrm{T}_{\mathrm{g}} \\
/ \mathrm{K}\end{array}$ & $\begin{array}{c}\mathbf{W}_{1 / 2 \mathrm{~h}} \\
/ \mathrm{K}\end{array}$ & $\begin{array}{c}\mathrm{E}_{293}^{\prime} \backslash \mathrm{E}^{\prime} \mathrm{r} \\
/ \mathrm{MPa}\end{array}$ & $\begin{array}{c}\mathrm{M}_{\mathrm{c}\left(\mathrm{E}^{\prime} r\right)} \\
/ \mathrm{g} \mathrm{mol}^{-1}\end{array}$ \\
\hline $2 M$ & $363 / 431$ & - & $2836 \backslash-$ & - \\
\hline $2 \mathrm{M} / \mathrm{EDDT}$ & 331 & 26.5 & $1976 \backslash 27.7$ & 374.2 \\
\hline $2 \mathrm{M} / \mathrm{DAS}$ & 351 & 26.0 & $2908 \backslash 26.5$ & 428.8 \\
\hline
\end{tabular}
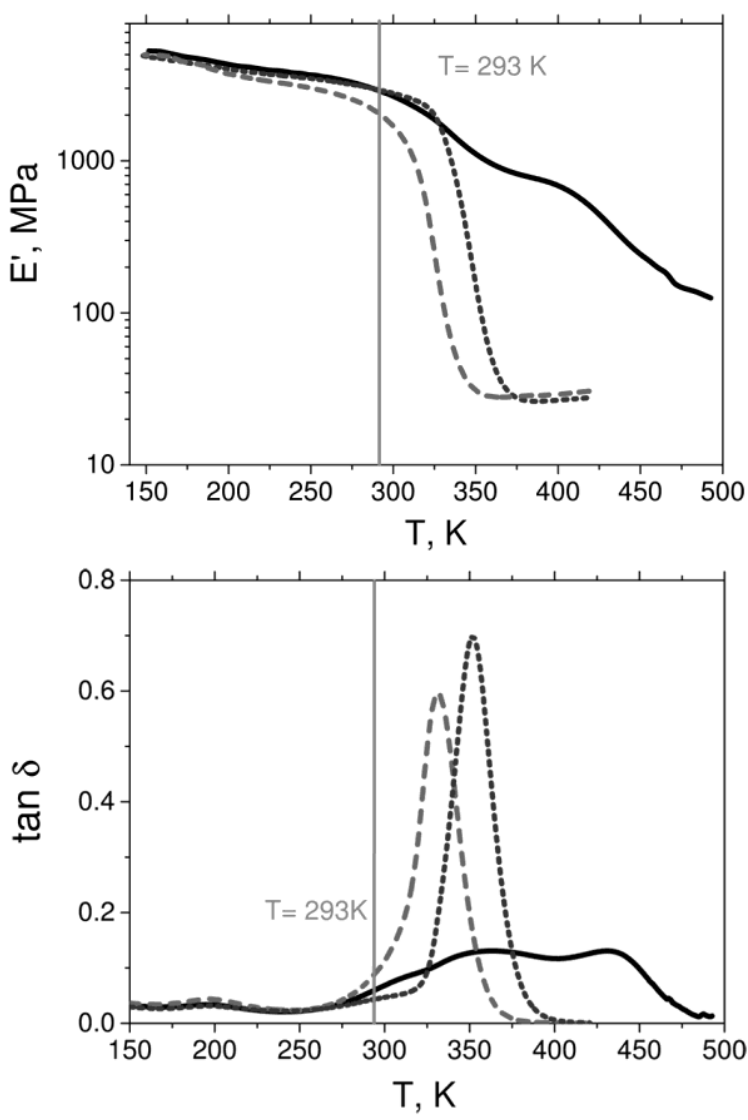

FIGURE 3 Storage modulus ( $E^{\prime}$, top) and loss factor (tan $\delta$, bottom) plots for reference sample $2 \mathrm{M}(-)$ and regulated networks, i.e. 2M/EDDT (---) and 2M/DAS (...).

The measured narrow glass transitions $\left(w_{1 / 2 \mathrm{~h}}=\right.$ $26.0 \mathrm{~K}$ for $2 \mathrm{M} / \mathrm{DAS}$ and $26.5 \mathrm{~K}$ for $2 \mathrm{M} / \mathrm{EDDT}$ ) confirm the reported higher structural homogeneity for the CTA-based samples. The features of their crosslinks are reflected by the modulus behavior in the rubbery plateau region $\left(E_{r}{ }_{r}\right)$ that could be related to the network density and the expansion ability of crosslinks. The values of $M_{c}$ were estimated using the kinetic theory of rubber elasticity as follows (eq 10).

$M_{c}=3 \rho_{p}\left(\frac{R T}{E_{r}^{\prime}}\right)$

where $\rho_{p}$ is the polymer bulk density, $R$ is the gas constant, $T$ is the absolute temperature and $\mathrm{E}^{\prime}{ }_{\mathrm{r}}$ is the storage elastic modulus in the rubbery plateau region (Table 3$).{ }^{26}$ The uncertainty of 
the $M_{c}$ values could be assigned to an incomplete conversion of monomers in the network and formation of cyclic structures that are an elastically inactive part of the networks. However, for both CTA-based samples we have confirmed an increase in conversion compared to $2 \mathrm{M}$. Additionally, $\beta$-allyl sulfones are known to better coreact with methacrylates as their ratio of the rate constant for chain propagation $\left(k_{p}\right)$ to the rate constant of chain transfer $\left(k_{t r}\right)$ during photopolymerization, the chain transfer constant $\left(C_{\mathrm{tr}}\right)$, is close to $1^{27}$ whereas $C_{\mathrm{tr}}<0.5$ for thiols. ${ }^{28} \beta$-Allyl sulfones can undergo further crosslinking due to subsequent reaction of the newly formed double bonds after chain transfer. It is also known that the sulfonegroups (2M/DAS) increase $\mathrm{T}_{\mathrm{g}}$ and that thioether bridges (2M/EDDT) tend to soften the photopolymer networks.

However, by the comparison of the determined $M_{c}$ values from swelling (Table 2) and DMA (Table 3 ) the proportionality for the samples $2 \mathrm{M} / \mathrm{EDDT}$ and $2 \mathrm{M} / \mathrm{DAS}$ can be seen. The $\beta$-allyl sulfone-based sample 2M/DAS presents a less crosslinked photopolymer with a more uniform network architecture in comparison to the 2M/EDDT network. The storage modulus at ambient temperature $E^{\prime}{ }_{293 \mathrm{~K}}$ is with $2908 \mathrm{MPa}$ significantly higher for the $\beta$-allyl sulfone-based sample when compared to the rather soft thioether network 2M/EDDT with a value reduced by roughly $30 \%$ (1976 $\mathrm{MPa})$. Overall, this leads to the assumption that at lower temperatures $\left(T<T_{g}\right)$ the combination of network density and free-volume (see PALS study) contributes to the detected modulus, but at temperatures above $\mathrm{T}_{\mathrm{g}}$ the network density of the measured material as well as the flexibility of chains are the major factors for the response in modulus. A further indication for that statement is the slope of the $\tan \delta$ plot at ambient conditions $\left(\mathrm{T}<\mathrm{T}_{\mathrm{g}}\right)$. Here, the network 2M/DAS with higher bulk density exhibits the smallest slope.

\section{Investigation of the microstructure}

\section{Void size}

Based on a PALS study, the influence of the two different CTAs (i.e. thiol EDDT, $\beta$-allyl sulfone DAS) on the final network architecture in terms of microstructural characteristics such as freevolume of voids and its distribution should be interpreted. PALS experiments of all three samples were carried out in air at a temperature of $296 \mathrm{~K}$, which was chosen to ensure that all measured networks are in the glassy state (below $\mathrm{T}_{\mathrm{g}}$ ) and their respective storage moduli are in the same order of magnitude (Table 3). Doses from positron irradiation of samples were set small enough to not break the crosslinked structure of the samples during the PALS measurements. The estimation of doses was performed according to literature. ${ }^{29}$ The discrete lifetime components $\tau_{\text {o-Ps }}$ from PATFIT-88 analysis for the three investigated photopolymers $2 \mathrm{M}$, 2M/EDDT and 2M/DAS were determined (Figure S1). The values of $\tau_{\text {o-Ps }}$ are evaluated as a sum of fifteen spectra that exhibit constant behavior without changes in time. From the average values of o-Ps lifetimes $\left(\tau_{\mathrm{o}-\mathrm{Ps}_{\mathrm{s}}}\right)$, the average radii of voids $\left(r_{h}\right)$ were calculated by applying eq 8 . The $2 \mathrm{M} / \mathrm{DAS}$ sample with an average lifetime of 1.79 ns exhibits smaller voids with an equivalent radius of $0.267 \mathrm{~nm}$ compared to the 2M/EDDT and $2 \mathrm{M}$ samples which contain a comparable size of voids with $0.286 \mathrm{~nm}$ and $0.288 \mathrm{~nm}$, respectively (Table 4). This result could be explained by the curing characteristics of the different formulations. ${ }^{8}$ The dimethacrylate reference $2 \mathrm{M}$ reaches the gel point (vitrification; transition from liquid to solid) already at conversions $<20 \%$ and for the remainder of the curing reaction the material cannot flow or relax anymore. As a result, the crosslinked polymer chains cannot move closer to each other and this could yield a larger void size. With the incorporation of CTAs, the gel point can be moved to higher conversions thus reducing the overall shrinkage stress. This effect is more pronounced for DAS-based resins. 
Hence, the liquid state of $2 \mathrm{M} / \mathrm{DAS}$ samples is significantly extended during curing and this could give the crosslinked polymer chains the option to stack closer to each other and form smaller voids compared to the samples $2 \mathrm{M}$ and 2M/EDDT.

Other important factors that directly influence free-volume are the overall mobility of chains as well as the segmental movements regarding the mobility of crosslinks and pendant groups. In the reference mixture $2 \mathrm{M}$, the more flexible areas with D3MA-units can contribute to the enlarged free-volume void size with the tendency to poorer polymer packing efficiency. The influence of the comonomer mobility on the network structure was discussed in a recent study by the group of J. W. Stansbury. ${ }^{13}$ In addition, pendant unreacted double bonds may contribute to a bigger free-volume. This is supported by the lower double bond conversion ( $80 \%$ ) of the pure dimethacrylate mixture $(2 \mathrm{M}){ }^{8}$ The bigger average size of voids in the mixture $2 \mathrm{M}$ can be attributed to lower packing tendency due to low flexibility of crosslinks as well as to unreacted double bonds of approximately $20 \%$.

In dimethacrylate photopolymerization, the reaction is dominantly diffusion controlled and the addition of CTAs, such as $\beta$-allyl sulfone DAS and dithiol EDDT, prolongs gelation at which phase transition is not controlled by diffusion and thus double bond conversion shifts to higher values. This is caused by the formation of shorter polymer backbones and more chain ends through chain transfer. The change towards a mixed chain growth / step growthlike mechanism ultimately leads to more homogeneous network architectures with smaller free-volume void sizes (Table 4). Furthermore, the incorporation of polar bridges (i.e. $\mathrm{SO}_{2}$ group of $\beta$-allyl sulfones) within the 2M/DAS sample can cause stronger interactions between polymer chains compared to the polar, flexible thio-ether bridges of the dithiol-based network 2M/EDDT. This could be another explanation for the lower average void size of the 2M/DAS sample in comparison to the sample 2M/EDDT. A maximal entropy lifetime (MELT) analysis regarding lifetime distribution was also performed on all investigated samples. Figure 4 shows the $\tau_{o-P s}$ distributions for the measurement series, which reflect the distribution of void sizes in a given sample. A measure for the homogeneity of void sizes between chains can be expressed by the width of the distribution at half peak height $\left(w_{1 / 2}\right.$; Table 4). The $w_{1 / 2 h}$-values can be viewed as proportional to the void size distributions of the polymers. L. Rey et al. $^{30}$ first mentioned the mutual correlation between the width of o-Ps lifetime distribution and heterogeneity in thermosets. The samples 2M/DAS and $2 \mathrm{M} /$ EDDT with narrower distributions $\left(\mathrm{w}_{1 / 2 \mathrm{~h}}=\right.$ $0.25 ; \mathrm{w}_{1 / 2 \mathrm{~h}}=0.26$ ) suggest a more homogeneous network structure than for the reference $2 \mathrm{M}\left(\mathrm{w}_{1 / 2 \mathrm{~h}}=0.35\right)$. The slightly narrower distribution for 2M/DAS compared to 2M/EDDT can be explained by $C_{t r}$, which is $~ 1$ for $\beta$-allyl sulfones with methacrylates. This implies a more homogeneous curing reaction in comparison to the thiol-methacrylate resin $2 \mathrm{M} /$ EDDT with a $\mathrm{C}_{\mathrm{tr}}<0.5$ for thiols.

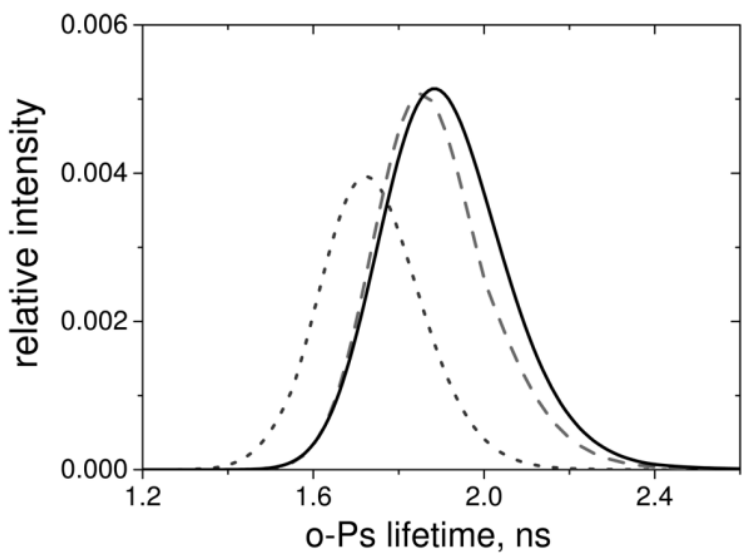

FIGURE 4 Distributions of the o-Ps lifetimes for the samples $2 \mathrm{M}(-), 2 \mathrm{M} / \mathrm{EDDT}(---)$ and 2M/DAS (...). 
TABLE $4 \tau_{\mathrm{o}-\mathrm{Ps}_{\mathrm{s}}}$ lifetime (PATFIT), calculated $\mathrm{r}_{\mathrm{h}}$ and width of lifetime distribution $w_{1 / 2 h}$ (MELT) for investigated samples.

\begin{tabular}{l|cc|c}
\hline & \multicolumn{2}{|c|}{$\begin{array}{c}\text { PATFIT-88, } \\
\text { discrete values of } \tau_{\text {o-ps }}\end{array}$} & $\begin{array}{c}\text { MELT, } \\
\text { distribution of } \tau_{\text {o-ps }}\end{array}$ \\
\hline sample & $\begin{array}{c}\tau_{\text {o-Ps }} \\
/ \mathbf{n s}\end{array}$ & $\begin{array}{c}\mathbf{r}_{\mathrm{h}} \\
/ \mathbf{n m}\end{array}$ & $\begin{array}{c}\mathbf{W}_{1 / 2 \mathrm{~h}} \\
/ \mathbf{n s}\end{array}$ \\
\hline $2 \mathrm{M}$ & $2.00 \pm 0.01$ & $0.288 \pm 0.001$ & 0.35 \\
\hline $2 \mathrm{M} / \mathrm{EDDT}$ & $1.98 \pm 0.01$ & $0.286 \pm 0.001$ & 0.26 \\
\hline $2 \mathrm{M} / \mathrm{DAS}$ & $1.79 \pm 0.01$ & $0.267 \pm 0.001$ & 0.25
\end{tabular}

\section{Relative intensity of o-Ps in relation to number} density of voids

The free-volume fractions of the investigated materials at room temperature can be compared by a simple approach via a phenomenological relationship (eq 11) used by Kobayashi et al. ${ }^{31}$ or Wang et al. ${ }^{32}$, where $\mathrm{C}$ is a material constant (depending on the polymer structure), $V_{h}$ is the free-volume of holes calculated from $\tau_{0-P s}$ PALS data and $I_{3}$ is the relative intensity of o-Ps, which is linearly correlated to the number of free-volume holes.

$\mathrm{f}=\mathrm{CV}_{\mathrm{h}} \mathrm{I}_{3}$

Thus, $\mathrm{C} \times \mathrm{I}_{3}$ corresponds to the number of voids per volume unit. The value of $C$ can be usually obtained from the comparison of $f$ with a known value of fraction estimated by the PVT method. However, the main problem is the value of $I_{3}$. Several factors can influence the Ps formation thus changing $I_{3}$ (e.g. chemical properties of some functional groups, electron or positron affinity to the material $\left.{ }^{33}\right)$. It is impossible to isolate this effect from the contribution of the number density of holes to $\mathrm{I}_{3}$ thus criticizing eq 11 . On the other hand Jamieson et al. ${ }^{34}$ argued, that it can still be applied if the time dependence of $I_{3}$ is negligible during PALS measurements and if the sample is rejuvenated prior to the measurement. Anyways, eq 11 must be used cautiously.

The values of $V_{h} \times I_{3}$ for the three measured samples are listed in Table 5 . The highest value for $\mathrm{f} / \mathrm{C}$ at room temperature is reached for reference $2 \mathrm{M}$. In the case of samples with CTA, the values for the free-volume fraction are reduced. By using the empirical constant $\mathrm{C}=$ $0.018 \mathrm{~nm}^{-3}$ from literature ${ }^{35}$ a reasonable average value $f=0.026$ for the tested samples is obtained and can be compared to the value of free-volume fraction 0.025 at $T_{\mathrm{g}}$ according to the Williams, Landel and Ferry model. ${ }^{36}$ The presence of sulfur in the samples with CTA could inhibit Ps formation and then reduce values of $\mathrm{I}_{3}{ }^{37}$ (Table 5). This effect could change the correct value of fraction $f$ estimated by this approach. Another way to determine the freevolume fraction from PALS experiments is from the measured (or known) $\tau_{3}$ temperature dependence. $^{38}$

The estimated reduction of the free-volume fraction can be correlated with the occurrence of gelation at higher conversion and the concomitant reduction of shrinkage stress for regulated photopolymer networks (i.e. 2M/DAS and $2 \mathrm{M} / \mathrm{EDDT}$ ). This goes hand in hand with the previous interpretation of reduced void size and void size distribution. The regulated network 2M/DAS exhibits smaller voids with a more narrow distribution.

TABLE 5 Relative intensity $I_{3}$, free-volume $V_{h}$ and $\mathrm{f} / \mathrm{C}=\mathrm{V}_{\mathrm{h}} \times \mathrm{I}_{3}$ for investigated samples.

\begin{tabular}{lccc}
\hline sample & $\begin{array}{c}\mathrm{I}_{3} \\
/ \%\end{array}$ & $\begin{array}{c}\mathrm{V}_{\mathrm{h}} \\
/ \mathrm{nm}^{3}\end{array}$ & $\begin{array}{c}\mathrm{V}_{\mathrm{h}_{3}} \\
/ \mathrm{nm}^{3}\end{array}$ \\
\hline $2 \mathrm{M}$ & 17.5 & 0.100 & 0.0175 \\
\hline M/EDDT & 16.1 & 0.098 & 0.0158 \\
\hline M/DAS & 12.8 & 0.080 & 0.0102 \\
\hline
\end{tabular}

\section{CONCLUSIONS}

Using $\beta$-allyl sulfones as AFCT reagents for the regulation of photopolymer networks serves as a viable approach to establish photopolymerization in more advanced fields of application (e.g. 3D-printing, tissue engineering, dental medicine). The thermomechanical and mechanical properties of said modified networks have already been studied and 
compared to state-of-the-art photopolymers with improved tunability (i.e. thiol-ene networks). With the help of this PALS study we have gained valuable insight about the microstructure of regulated dimethacrylate networks through the void size $\left(r_{h}\right)$ and the width of the free-volume voids size distribution $\left(w_{1 / 2 h}\right)$. The average void size is smallest for the $\beta$-allyl sulfone-based sample $2 \mathrm{M} / \mathrm{DAS}$ with an equivalent radius of $0.267 \mathrm{~nm}$. The implementation of $\beta$-allyl sulfones into a dimethacrylate-based resin yields a more organized polymer network structure forming smaller and more uniform void sizes which is shown by the sharp free-volume size distribution. These findings were further correlated with additional macroscopic studies providing packing density (calculated) and macroscopic characteristics obtained from bulk density, swelling and DMTA measurements. Overall, the differences in network structure of regulated CTA-based photopolymer networks as well as the relations between void formation, crosslinking density and macroscopic characteristics such as shrinkage stress and mechanical properties were elucidated. It can be concluded, that shrinkage stress reduction might support a closer packing, smaller voids and a more narrow void size distribution in the final photopolymer network. A more homogeneous network structure for CTA-based samples has been additionally confirmed by the combination of DMTA and PALS results.

\section{ACKNOWLEDGEMENTS}

Support from the Christian Doppler Research Association and the company Ivoclar Vivadent AG for the project "Photopolymers in Digital and Restorative Dentistry" is gratefully acknowledged. The authors also wish to thank the Agency VEGA Slovakia, project no. 2/0164/14, Ernst Mach grant supported by Agency SAIA and the Austrian Science fund (FWF) for funding (project P27059). Furthermore, the authors thank Dr. J. Pavlinec and $\mathrm{Dr}$. R. Liska for fruitful discussions and $\mathrm{Z}$.
Nogellova for her help with the bulk density measurements.

\section{REFERENCES AND NOTES}

1. Y. Abe. DIC Tech. Rev. 2005, 11, 1-20.

2. C. Dworak, T. Koch, F. Varga, R. Liska. J. Polym. Sci., Part A: Polym. Chem. 2010, 48, 2916-2924.

3. J. Torgersen, X.-H. Qin, Z. Li, A. Ovsianikov, R. Liska, J. Stampfl. Adv. Funct. Mater. 2013, 23, 4542-4554.

4. S. C. Ligon-Auer, M. Schwentenwein, C. Gorsche, J. Stampfl, R. Liska. Polym. Chem. 2016, 7, 257-286.

5. C. E. Hoyle, C. N. Bowman. Angew. Chem., Int. Ed. 2010, 49, 1540-1573.

6. G. Moad, E. Rizzardo, S. H. Thang. Polymer 2008, 49, 1079-1131.

7. C. Gorsche, M. Griesser, G. Gescheidt, N. Moszner, R. Liska. Macromolecules 2014, 47, 7327-7336.

8. C. Gorsche, T. Koch, N. Moszner, R. Liska.

Polym. Chem. 2015, 6, 2038-2047.

9. R. A. Pethrick. Prog. Polym. Sci. 1997, 22, 1-

47.

10. D. M. Schrader, Y. C. Jean, Editors. Studies in Physical and Theoretical Chemistry, Vol. 57:

Positron and Positronium Chemistry; Elsevier, 1988.

11. Y. C. Jean, T. C. Sandreczki, D. P. Ames. J. Polym. Sci., Part B: Polym. Phys. 1986, 24, 12471258.

12. G. Dlubek, J. Stejny, M. A. Alam. Macromolecules 1998, 31, 4574-4580.

13. C. S. Pfeifer, Z. R. Shelton, R. R. Braga, D. Windmoller, J. C. Machado, J. W. Stansbury. Eur. Polym. J. 2011, 47, 162-170.

14. L. Kwisnek, M. Kaushik, C. E. Hoyle, S. Nazarenko. Macromolecules 2010, 43, 38593867.

15. N. Moszner, F. Zeuner, I. Lamparth, U. K. Fischer. Macromol. Mater. Eng. 2009, 294, 877886.

16. P. Esfandiari, S. C. Ligon, J. J. Lagref, R. Frantz, Z. Cherkaoui, R. Liska. J. Polym. Sci., Part A: Polym. Chem. 2013, 51, 4261-4266. 17. P. J. Flory. J. Chem. Phys. 1950, 18, 108-111. 
18. J. Brandrup, E. H. Immergut. Polymer Handbook, Solubility Parameter Values; Wiley: New York, 1989.

19. A. Shukla, M. Peter, L. Hoffmann. Nucl. Instrum. Methods Phys. Res., Sect. A 1993, 335, 310-317.

20. P. Kirkegaard, M. Eldrup, O. E. Mogensen, N. J. Pedersen. Comput. Phys. Commun. 1981, 23, 307-335.

21. M. Eldrup, D. Lightbody, J. N. Sherwood. Chem. Phys. 1981, 63, 51-58.

22. S. J. Tao. J. Chem. Phys. 1972, 56, 54995510.

23. H. Nakanishi, Y. C. Jean. Stud. Phys. Theor. Chem. 1988, 57, 159-192.

24. A. A. Askadskii. Pure Appl. Chem. 1976, 46, 19-27.

25. J. P. Pascault, H. Sautereau, J. Verdu, R. J. J. Williams. Thermosetting Polymers: Basic physical of networks: New York, 2002.

26. A. V. Tobolsky. J. Polym. Sci., Part C: Polym. Symp. 1965, 9, 157-179.

27. G. F. Meijs, E. Rizzardo, S. H. Thang. Polym. Bull. 1990, 24, 501-505.

28. L. Lecamp, F. Houllier, B. Youssef, C. Bunel. Polymer 2001, 42, 2727-2736.
29. T. Suzuki, Y. Namito, Y. Oki, M. Numajiri, T. Miura, H. Hirayama, K. Kondo, Y. Ito. KEK Proc. 1994, 94, 91-103.

30. L. Rey, J. Galy, H. Sautereau, G. P. Simon, W. D. Cook. Polym. Int. 2004, 53, 557-568.

31. Y. Kobayashi, W. Zheng, E. F. Meyer, J. D. McGervey, A. M. Jamieson, R. Simha. Macromolecules 1989, 22, 2302-2306. 32. Y. Y. Wang, H. Nakanishi, Y. C. Jean, T. C. Sandreczki. J. Polym. Sci., Part B: Polym. Phys. 1990, 28, 1431-1441.

33. O. E. Mogensen. J. Phys. IV 1993, 4, 1-15. 34. A. M. Jamieson, B. G. Olson, S. Nazarenko. 2010, pp 473-522.

35. P. N. Patil, S. K. Rath, K. Sudarshan, D. Dutta, M. Patri, P. K. Pujari. AIP Conf. Proc. 2010, 1313, 298-300.

36. M. L. Williams, R. F. Landel, J. D. Ferry. J.

Am. Chem. Soc. 1955, 77, 3701-3707.

37. W. Salgueiro, A. Marzocca, A. Somoza, G. Consolati, S. Cerveny, F. Quasso, S. Goyanes.

Polymer 2004, 45, 6037-6044.

38. P. Bandzuch, J. Kristiak, O. Sausa, J. Zrubcova. Phys. Rev. B: Condens. Matter Mater. Phys. 2000, 61, 8784-8792. 
GRAPHICAL ABSTRACT

Helena Švajdlenková, Ondrej Šauša, Johannes Steindl, Thomas Koch, Christian Gorsche

Microstructural PALS study of regulated dimethacrylates: Thiol- versus $\beta$-allyl sulfone-based networks

Using chain transfer reagents (e.g. thiols or $\beta$-allyl sulfones) for the toughening of photopolymer networks promises great potential for advanced fields of application such as 3D-printing and biomedicine. A PALS study was conducted in order to gain more insight about the microstructure of such modified networks and correlations with macrostructural properties such as polymerization induced shrinkage stress, glass transition, bulk density and swelling behavior have been drawn.

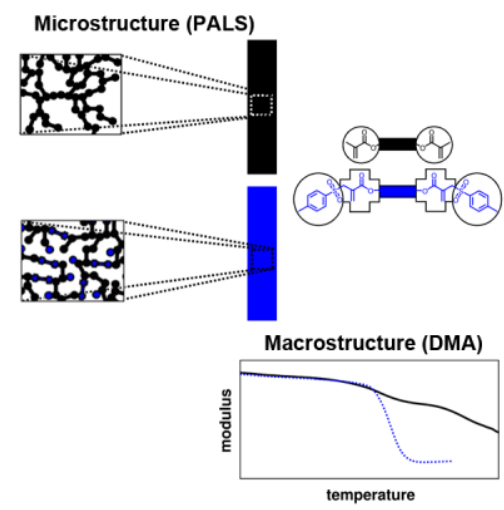

